Abstracta Iranica

Revue bibliographique pour le domaine irano-aryen

Volume 34-35-36 | 2017

Comptes rendus des publications de 2011-2013

\title{
Ali Bahadori. TaHt-e Jamšìd : Nowrūz va Mehrgān / Persepolis: Nowruz and Mehrgan
}

\section{Rémy Boucharlat}

\section{(2) OpenEdition}

\section{Journals}

Édition électronique

URL : http://journals.openedition.org/abstractairanica/41649

DOI : 10.4000/abstractairanica.41649

ISSN : 1961-960X

Éditeur :

CNRS (UMR 7528 Mondes iraniens et indiens), Éditions de l'IFRI

Référence électronique

Rémy Boucharlat, « Ali Bahadori. Taht-e Jamšīd : Nowrūz va Mehrgān / Persepolis: Nowruz and Mehrgan », Abstracta Iranica [En ligne], Volume 34-35-36 | 2017, document 69, mis en ligne le 15 juillet 2016, consulté le 04 octobre 2020. URL : http://journals.openedition.org/abstractairanica/41649; DOI : https://doi.org/10.4000/abstractairanica.41649

Ce document a été généré automatiquement le 4 octobre 2020.

Tous droits réservés 


\title{
Ali Bahadori. TaHt-e Jamšìd : Nowrūz va Mehrgān / Persepolis: Nowruz and Mehrgan
}

\author{
Rémy Boucharlat
}

\section{RÉFÉRENCE}

Ali Bahadori. « TaH̆t-e Jamšĩd : Nowrūz va Mehrgān / Persepolis: Nowruz and Mehrgan ». Majalle-ye bāstānšenāsī va tārīH / IJAH, vol. 25, № 2, serial No. 50, 2012, p. 108-128.

1 L'A. fait l'hypothèse que Persépolis était le lieu de cérémonies qui n'étaient pas limitées à celles du Nouvel An, mais pouvait servir aussi à celle de Mehrgān à l'automne. Cela suppose que Persépolis était bien un lieu cérémoniel et que le roi s'y rendait régulièrement. En faveur de réalité de la fête de Mehrgān l'A. recherche les indices de la présence du culte de Mithra à la cour achéménide, en particulier à partir des basreliefs. Le sujet est important, mais pas très neuf, et ne peut être traité en un seul article ; il suscitera sans doute des études plus approfondies.

\section{AUTEURS}

RÉMY BOUCHARLAT

CNRS, Lyon 